\title{
Teaching for Understanding and Senior Secondary Students' Learning Achievement in Solid Geometry
}

\author{
Nduka Wonu ${ }^{1}$, Charles-Ogan Gladys $(\mathrm{PhD})^{2}$ \\ ${ }^{I}$ Department of Mathematics/Statistics, Faculty of Natural and Applied Sciences Ignatius Ajuru University of \\ Education, Port Harcourt, Nigeria. \\ ${ }^{2}$ Department of Curriculum Studies and Educational Technology, Faculty of Education, University of Port
} Harcourt

\begin{abstract}
This study was a quasi-experimental design aimed at exploring the effect of Teaching for Understanding (TfU) instructional model on the solid geometry learning achievement of Senior Secondary School I (SSSI) students in Emohua Local Government Area (LGA) of Rivers State, Nigeria. A total of 58 SSSI students participated in the study. The instrument used for data collection in this study was a researcher designed and validated the 50-item multiple-choice test, Solid Geometry Achievement Test (SGAT). The reliability of SGAT was determined using the Kuder-Richardson, KR-21 method to obtain an index of 0.84. Two research questions and two hypotheses guided the study. The research questions were answered using mean and standard deviation whereas the hypotheses were tested using the Analysis of Covariance (ANCOVA) at .05 alpha level. The students in the experimental group were taught using TfU model whereas the students in the control group were taught using the Problem-based Learning (PbL) model. The findings were that students taught using the TfU model improved in learning more than those who were taught using PbL model over time. There was a significant effect of the TfU model on the learning achievement of senior secondary students in solid geometry; however, there was no significant difference between the respective mean learning achievement scores of the male and the female students taught solid geometry using the TfU instructional model over the PbL model. The study recommended among others that teachers of mathematics should try to adopt the TfU model in the teaching of solid geometry as this instructional model enables the student in the transfer of learned concept, facts and procedures in a new situation.
\end{abstract}

Keywords: Teaching for understanding, senior secondary students, learning achievement, Solid geometry

\section{Introduction}

Teaching for Understanding (TfU) is a constructivist instructional model based on the assumptions of constructivism (Perkins, 2006). This model of instruction was designed and developed by Tina Blythe and associates at the Harvard Graduate School of Education (Perkins \& Blythe, 1994). The TfU model is a flexible framework for rethinking pedagogy (Lulee, 2010). The TfU framework contains four basic components, namely; Generative Topics, Understanding Goals, Performances of Understanding and On-going Assessment. The TfU model puts understanding first in the design of pedagogy (Perkins, 1994). Perkins and Blythe (1994) further indicated that understanding has to do with the ability to accomplish a wide range of complex problemsolving on a topic that requires explanation, identifying facts and example and showcasing the topic in a novel pattern among others.

Understanding in the TfU framework entails the ability of a student to interpret or explain a studied concept correctly and clearly and also transfer such ideas to novel situations having some basic features with real life situations used for commencing the learning. Therefore, understanding rather than coverage of curriculum content is an essential principle in TfU. Perkins and Blythe (1994) consider Performances of Understanding ( $\mathrm{PoU}$ ) as the core of developing understanding. The PoU by the learners helps them to temporarily express their understanding and aid the teacher to evaluate the level of understanding of the students for the modification of instruction accordingly (Lulee 2010). A good PoU would present proof for evaluations, therefore, it is vital to make students' thinking visible (Ritchhart \& Perkins, 2008). The Ongoing Assessment $(\mathrm{OA})$ is used to quantify understanding and provide the information needed by the instructors to improve planning and instruction ( Lulee 2010).

Teaching for meaning and understanding has always proven to be effective in mathematics education (Serio, 2014). Emphasis on teaching for meaning has positive effects on the learning of the students, improvement of previous learning, promotion of retention and has the capacity to propel the application of the understanding or ideas in new situations (Grouws \& Cebulla, 2000). Transfer of learned concept, facts and procedures in a new situation in any discipline is greatly influenced by the level of understanding rather than just memorising sets of facts or following a fixed set of procedures (Bransford, Brown \& Cocking, 2000). The TfU model promotes deep learning, over covering a wide range of materials and application of understanding to 
Teaching for Understanding and Senior Secondary Students' Learning Achievement in Solid ..

real-life problem-solving over performance on tests. The students must grasp facts and ideas in the context of a given concept and reorganise for effortless retrieval and use. Learners' engagement in mathematical communication is important in TfU framework (Bransford, Brown, \& Cocking 2000, Morocco \& Bremer 2003, Serio 2014).

Carson (2011) evaluated a whole school CPD project in south-west Scotland. The aims of the initiative were to implement the TfU framework for teaching and learning improvement across the school, to advance stability of planning across the school and to increase collaborative practice among staff. Questionnaires and semi-structured interviews were used for data collection. Five research questions guided the investigation. The report suggested that adoption of the TfU framework led to improvements in teaching and learning, although the gains were dependent on the subject taught and the career phase of the teacher. The report indicated that the entire school CPD project led to enhanced collaborative reflection on planning but numerous factors such as time and issues bordering on professional autonomy were found to hamper the adoption of the approach by more experienced teachers. The underlying principles of the framework were adopted by the teachers.

The efficacy of TfU in the medical classrooms using multimedia design principles was investigated by Issa, Mayer, Schuller, Wang, Shapiro, and DaRosa, (2013). The study was aimed at ascertaining whether the review of medical instruction based on the fact-based standard of multimedia would yield improved retention and long-term transfer among medical students. The results indicated that the experimental group who received instruction using Mayer evidence-based principles of multimedia design significantly outperformed the control group who were taught through a bullet point-based PowerPoint on shock development over retention and delayed tests of transfer after instruction. The experimental group also significantly outperformed the control group on immediate tests of transfer and retention. The study concluded that it had presented the first proof that the application of the principles of multimedia design to medical lectures has a statistically significant effect on variables of understanding among students.

Similarly, Duyilemi and Bolajoko (2014) studied the effects of the constructivists' instructional strategies (CIS) on the achievement and retention abilities of students in biology and found that CIS significantly improved students' achievement and retention. The male participants outperformed the female participants in the experimental group; however, the observed mean difference was not statistically significant at.05 alpha level. Umoke and Nwafor (2014) explored the effect of instructional simulation methods on the achievement secondary school students in biology and the findings among others results established that instructional simulation methods promoted higher achievement in biology in comparison with the traditional method. The male and the female participants did not significantly defer in term of achievement when taught using instructional simulation methods. Abiodun and Jonathan (2010) also established no significant difference between the male and female learners instructed using the constructivist instructional model. Other recent studies have also shown that constructivist instructional models were capable of reasonably reducing the learning achievement gap between the male and the female students (Okoronka \& Bitrus 2014, Dorji, Panjaburee \& Srisawasdi, 2015).

\section{Statement of the problem}

The underachievement of students in mathematics is a recurring decimal. Ogunkunle (2009) established that mathematics teachers adopt only lecture method in teaching mathematics in schools. The use of lecture method has not been helpful in the improvement of the learning achievement of students in the subject. Due to the importance of mathematics in the scientific and technological development of the nation, researchers in mathematics education have adopted several constructivist instructional models to improve the learning achievement of students in mathematics. However, to the best of the knowledge of the researchers, no study conducted in Emohua LGA has explored the effectiveness of TfU model in the improvement of the learning achievement of students in solid geometry. In line with the foregoing, the present study is a peer into the effect of TfU model in enhancing the learning achievement of students in solid geometry in Emohua LGA.

\section{Aim and objectives of the study}

The main aim of the present study was to investigate the effect of TfU instructional model on the learning achievement of SSSI students in solid geometry. Specifically, the objectives of the study were to:

1. Determine the effect of the TfU model on the learning achievement of senior secondary students in solid geometry.

2. investigate the difference between the respective mean learning achievement scores of the male and the female students taught solid geometry using the TfU model over the PbL model 
Teaching for Understanding and Senior Secondary Students' Learning Achievement in Solid ..

\section{Research questions}

The following research questions guided the study

1. What is the effect of the TfU model on the learning achievement of senior secondary students in solid geometry?

2. What is the difference between the respective mean learning achievement scores of the male and the female students taught solid geometry using the TfU model over the PbL model?

\section{Hypotheses}

The following research hypotheses which were tested at .05 alpha level guided the study

$\mathbf{H}_{01}$ : There is no significant effect of the TfU model on the learning achievement of senior secondary students in solid geometry.

$\mathbf{H}_{02}$ : There is no significant difference between the respective mean learning achievement scores of the male and the female students taught solid geometry using the TfU instructional model over the PbL model

\section{Methodology}

Research Design: The study adopted the quasi-experimental design. The purpose was to determine the relative effectiveness of the independent variable (i.e. instructional model) in enhancing students' achievement in solid geometry. The dependent variable was student learning achievement in solid geometry.

Population, Sample and Sampling Technique: The population of the study was all the 2,190 SSSI students in Emohua Local government Area (Rivers State Senior Secondary Schools Board, 2015). A total of 58 SSSI students participated in the study. Emohua Local Government Area purposively selected from the 23 LGAs in River State and it was used because of the availability of coeducational public senior secondary schools with a manageable number of students in each class. Two senior secondary schools were purposively selected for participation based on some criteria. Only one arm of SSSI class was randomly selected for participation in each of the two schools. The one arm of SSSI class in one of the two schools was randomly assigned to the experimental group and one arm of SSSI class in the other school was assigned to the control group.

Instrumentation: The instrument used for data collection in this study was a researcher designed and validated 50-item multiple-choice test titled Solid Geometry Achievement Test (SGAT). The SGAT is a quantitative measure of students' learning achievement in solid geometry. It was based on five content areas in solid geometry for SSSI students (total surface area and volume of solid shapes (cone, cylinder, cuboid, a cube, triangular and rectangular prism, pyramids) frustum of cone and pyramid and composite solids. The reliability of the SGAT was established using the Kuder-Richardson, KR-21 reliability method to obtain an index of 0.84 .

Experimental procedure: The prospective and retrospective assessments of the students using SGAT were done by specially briefed teachers. The scripts from the Pre-SGAT assessment were retrieved before commencing the appropriate instructions by the teacher. The researchers gave the teacher intensive training on the practical and the theoretical aspects of TfU instructional model. Prior to the instructions in the two groups, the researchers and the mathematics teachers in each group administered copies of the SGAT to the students as a pre-test and gave them 45 minutes to attempt the questions. The Pre-SGAT scripts were retrieved from the students when completed.

Intervention group: The experimental group were instructed using the TfU model. After the Pre-SGAT, the TfU instruction commenced. The teaching was designed around the TfU framework. The researchers and the TfUgroup teacher planned all the lesson units using the TfU framework planning sheet. This Framework has been used by Carson (2011) in the development of TfU curricular units. The framework aids teachers to focus on exactly what they want the students to understand, the way they aid students to enhance these understandings and how they monitor their progress and provide them with feedback. The TfU worksheet was used to direct the instruction in the classroom. This framework has four key components, (1) the Generative Topics (GT), (2) Understanding Goals (UG), (3) Performance of Understanding (PoU), and (4) Ongoing Assessment (OA).

The instruction commenced with the GT which was presented to the students as "throughlines" that help students to see the interrelationship among topics or themes. The GT were generated such that the underlying criteria for its development were fulfilled. To establish the understanding goals, the ideas, processes, relationships or questions that the students are meant to understand through enquiry were identified. Three or four goals specific to the particular unit or instruction were stated. This unit UG resulted to the design of three to five PoU aimed at aiding the students to reach the desired UG. During the implementation phase, the teacher asks questions such as What are you expected to understand? do you know how to derive the formula to apply? and What is your best approach to solving this task?. The students try to understand the question. They also try to find out the laws of mathematics that fit into the present problem. The teacher guided the students to use the law of mathematics to solve the problem.

The PoU clearly develops and demonstrate student understanding of vital UG. The PoU had three levels including the introductory, guided enquiry and more complex culmination performance. The PoU related 
Teaching for Understanding and Senior Secondary Students' Learning Achievement in Solid ..

directly to UG; increase and apply understanding through practice; employ multiple learning styles; encourage reflective engagement in challenging approachable task and demonstrate understanding. The teacher asks questions such as What do you derive from doing this activity? Can you use what you know to solve this problem and others? The teacher further gave students similar problems but on real life applications. The students indicate what they derive from the activities and use what they know to solve the present problem and other related real life tasks.

Ongoing assessment (OA) is made to be informative, and give feedback to the students about their task performance and directly related to the clearly defined UG. When doing this ongoing formative assessment, students were constantly focused on their UG and the way they intend to develop their understanding while providing information for the teacher to use in planning. The ongoing assessment was made relevant, explicit and have public criteria; involve frequent assessments; gained from multiple sources and able to gauge progress and inform planning. The teacher asks questions such as What criteria will help you understand the problem/task?; Are your criteria for understanding different from that of the teacher?; What is relevant in this problem?; Do other students understand the problem?; Was your performance good, better, best, or poor?; If poor how do you improve?; and Does the teacher and other students approve of your approach?. The responses to these questions were given directly or provided by students in the worksheets for the teacher's assessment. The activities were done in student groups, large class and individually.

Control group: Five (problem study, solution process planning, execution of solution plan, solution outcome evaluation, and problem mastery development) basic stages of problem-solving were adopted as the components of the PbL instructional model utilised in this group. The students in this group worked individually. Different solid geometry problems were solved by the teacher on the chalkboard whereas the students took notes of vital points and procedures used to obtain the answers. The students were also asked to solve related problem following the basic stages of problem-solving at the end of the instruction by the teacher.

Data analysis: The learning achievement of the students was assessed by asking each student to attempt the 50 questions (problems) on SGAT by ticking the correct option. A total of 2 marks were awarded for selecting a correct option whereas a score of zero was also awarded for selecting a wrong option, to sum up to $100 \%$. The Pre-SGAT and Post-SGAT scores of the students were used. To answer the research questions mean and standard deviation (SD) were used whereas to test the hypotheses at .05 alpha level, the Analysis of Covariance (ANCOVA) was used.

\section{Results}

Table 1: Mean, Standard Deviation (SD)and learning gain of participants taught using TfU models and PbL

\begin{tabular}{|l|l|l|l|l|l|l|l|l|l|l|}
\hline & & Pre-SGAT & Post-SGAT & Gain & & 95\% CI \\
\hline Model & $\mathbf{N}$ & $\overline{\mathrm{X}}$ & $\mathbf{S D}$ & $\overline{\mathrm{X}}$ & $\mathbf{S D}$ & $\overline{\mathrm{X}}$ & SD & LB & UB \\
& & & & & & & & \\
\hline $\mathrm{TfU}$ & 28 & 26.36 & 7.95 & 54.71 & 7.29 & 27.86 & 9.60 & 24.14 & 31.58 \\
\hline $\mathrm{PbL}$ & 30 & 26.73 & 5.72 & 48.60 & 8.16 & 21.87 & 10.54 & 17.93 & 25.80 \\
\hline
\end{tabular}

Source: field work 2016

Table 1 shows that the mean Pre-SGAT and Post-SGAT scores of students taught using TfU were $26.36 \pm 7.95$ and 54.71 \pm 7.29 respectively. The mean Pre-SGAT and Post-SGAT scores of students taught using $\mathrm{PbL}$ were $26.73 \pm 5.72$ and $48.60 \pm 8.16$ respectively. Table 1 further shows that the mean learning gain score of students instructed using TfU model was 27.86 \pm 9.60 , the 95\% confidence interval moved from 24.14 to 31.58 whereas that of those taught using $\mathrm{PbL}$ was $21.87 \pm 10.54$ and the $95 \%$ confidence interval moved from 17.93 to 25.80 .

Table 2: Mean, SD and mean gain of groups of the male and the female subjects instructed using TfU models and $\mathrm{PbL}$

\begin{tabular}{|c|c|c|c|c|c|c|c|c|c|c|}
\hline \multirow[b]{2}{*}{ Model } & \multirow[b]{2}{*}{ Sex } & \multirow[b]{2}{*}{$\mathbf{N}$} & \multicolumn{2}{|c|}{ Pre-SGAT } & \multicolumn{2}{|c|}{ Post-SGAT } & \multicolumn{2}{|c|}{ Learning gain } & \multicolumn{2}{|c|}{$95 \%$ CI } \\
\hline & & & & SD & & SD & & SD & LB & UB \\
\hline \multirow[t]{2}{*}{ TfU } & Male & 10 & 28.20 & 7.69 & 55.80 & 9.73 & 27.60 & 8.32 & 21.65 & 33.55 \\
\hline & Female & 18 & 25.33 & 8.12 & 54.11 & 5.76 & 28.00 & 10.47 & 22.79 & 33.21 \\
\hline \multirow[t]{2}{*}{$\mathrm{PbL}$} & Male & 12 & 27.67 & 5.10 & 46.50 & 8.99 & 18.83 & 12.69 & 10.77 & 26.90 \\
\hline & Female & 18 & 26.11 & 6.15 & 50.00 & 7.48 & 23.89 & 8.64 & 19.59 & 28.18 \\
\hline
\end{tabular}

Source: field work 2016

Table 2 shows that the mean Pre-SGAT and Post-SGAT scores of the male students taught using TfU

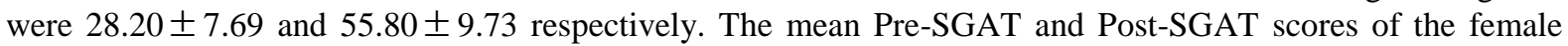
students taught using TfU were $25.33 \pm 8.12$ and 54.11 \pm 5.76 respectively. The mean Pre-SGAT and PostSGAT scores of the male students taught using PbL were $27.67 \pm 5.10$ and $46.50 \pm 8.99$ respectively. The mean 
Teaching for Understanding and Senior Secondary Students' Learning Achievement in Solid ..

Pre-SGAT and Post-SGAT scores of the female students taught using PbL were 26.11 \pm 6.15 and 50.00 \pm 7.48 respectively. Table 2 further shows that the mean learning gain of the male students taught using TfU model was $27.60 \pm 8.32$ and the $95 \%$ confidence interval moved from 21.65 to 33.55 . The mean learning gain of male students instructed with $\mathrm{PbL}$ was $18.83 \pm 12.69$. The $95 \%$ confidence interval moved from 10.77 to 26.90 . The mean learning gain of female students taught using TfU was $28.00 \pm 10.47$. The $95 \%$ confidence interval moved from 22.79 to 33.21 . The mean learning gain of female students taught using PbL was $23.89 \pm 8.64$. The $95 \%$ confidence interval moved from 19.59 to 28.18 .

Table 3: Simple main effects of treatment and sex on the learning achievement of students in solid geometry

\begin{tabular}{|l|l|l|l|l|l|l|}
\hline Source & SS & df & MS & F & p-value & Partial Eta Squared, $\eta^{2}$ \\
\hline Pre-SGAT & 7.449 & 1 & 7.449 & .120 & .730 & .002 \\
\hline Treatment & 534.861 & 1 & 534.861 & 8.646 & .005 & .138 \\
\hline Sex & 18.173 & 1 & 18.173 & .294 & .590 & .005 \\
\hline Error & 3340.371 & 54 & 61.859 & & & \\
\hline Total & 158044.000 & 58 & & & & \\
\hline Corrected Total & 3904.345 & 57 & & & & \\
\hline
\end{tabular}

The result as reflected in Table 3 shows that there was no significant effect of the TfU model on the learning achievement of senior secondary students in solid geometry $\left(\mathrm{F} 1,54=8.646, \mathrm{p}=.005, \eta^{2}=.138\right)$. The $\mathrm{H}_{01}$ was rejected at .05 alpha level. The result also shows that there was no significant difference between the respective mean learning achievement scores of the male and the female students taught solid geometry using the TfU instructional model over the PbL model $\left(\mathrm{F} 1,54=.294, \mathrm{p}=.590, \eta^{2}=.005\right)$. The $\mathrm{H}_{02}$ was upheld at .05 alpha level.

\section{Discussion of Findings}

\section{Teaching for understanding model and student learning achievement in solid geometry}

The result from Table 1 showed that the students taught using TfU model outperformed other students taught using $\mathrm{PbL}$ model. Particularly, the result established that students taught using TfU outperformed those taught using $\mathrm{PbL}$ model with a mean learning achievement gain score of 5.99. In addition, more relevant information was disclosed by the Post-SGAT on the impact of TfU on student mathematics learning progress. It showed that students instructed using the TfU model performed better than those taught using PbL with PostSGAT mean score of 6.11. This indicated that students in the experimental group benefited most from the instructions on solid geometry than those taught using PbL model. The superiority of TfU model over PbL model in the enhancement of the learning achievement of students in solid geometry may be related to the fact that the overarching goal of the TfU model is the development of the understanding of the students. The TfU model is known for granting the learners the opportunity to clearly and correctly interpret any learned concept in their own language for transfer in a novel situation. When put to the statistical test, the result of ANCOVA on Table 3 indicated that there was a significant effect of the TfU model on the learning achievement of senior secondary students in solid geometry $\left(\mathrm{F} 1,54=8.646, \mathrm{p}=.005, \eta^{2}=.138\right)$. The null hypothesis one was rejected at .05 alpha level. The present finding is consistent with an earlier study by Issa, et al (2013) on the exploration of the effect of TfU model in medical classrooms using multimedia design framework and found that the students who participated in the experimental group did better than those in the control group over delayed tests of transfer and that of retention after instruction as well as on immediate tests of transfer and retention.

\section{The TfU model and sex associated learning achievement in solid geometry}

The result from Table 2 showed that the female students taught using TfU model had the highest learning achievement gain in solid geometry in comparison to others. Specifically, female students taught using TfU model outperformed their female counterparts taught using PbL model with a mean learning gain difference of 4.11. The male students taught using TfU model also outperformed their male counterparts taught using $\mathrm{PbL}$ with a mean learning gain difference of 8.77. The mean difference in learning gain between the male and the female students taught using TfU and PbL models were 0.40 and 5.06 respectively and in favour of the female students. When put to the statistical test, the result from Table 3 shows that there was no significant difference between the respective mean learning achievement scores of the male and the female students taught solid geometry using the TfU instructional model over the $\mathrm{PbL}$ model. The $\mathrm{H}_{02}$ was upheld at .05 alpha level. The result was consistent with an earlier study by Peter, Abiodun and Jonathan (2010) which established no significant difference between the male and female learners instructed using the constructivist instructional model. 


\section{Conclusion}

It has been established that both senior secondary students taught using TfU and PbL instructional models improvement in learning achievement over time. The TfU model was found to be superior to PbL model with respect to the enhancement of the senior secondary students' learning achievement in solid geometry. The main effect of treatment was significant on the learning achievement of senior secondary students in solid geometry. There was no significant main effect of sex on the learning achievement of students in solid geometry among senior secondary students. The TfU model afforded the students to learn mathematics content deeply for transfer to related real life problems. Since the TfU model has been proven effective in teaching solid geometry among senior secondary students, the application of this instructional model should be extended to the teaching of other science subjects.

\section{Recommendations}

Based on the findings of the present study the following recommendations were made:

1. Teachers of mathematics should try to adopt the Teaching for the understanding model in the teaching of solid geometry. This instructional model enables the transfer of learned concept, facts and procedures in a new situation.

2. Mathematics teachers should engage both male and female students in mathematics problem-solving using teaching for understanding instructional model to minimise the existing gender inequity in mathematics achievement

[1]. Bransford, J. D., Brown, A. L., Cocking, R. R., Committee on Developments in the Science of Learning, \& National Research Council. (2000). How People Learn: Brain, Mind, Experience, and School: Expanded Edition (2nd ed.). National Academies Press

[2]. Carson, J. (2011). Teaching for understanding: Evaluating a whole school initiative. Teacher researcher programme $2009 / 2010$. Wallace Hall Academy. General teaching council Scotland.

[3]. Dorji, U., Panjaburee, P., \& Srisawasdi, N (2015). Gender differences in students' learning achievements and awareness through residence energy saving game-based inquiry playing. Journal of Computer Education. 2(2):227-243

[4]. Duyilemi, A.N \& Bolajoko, A.O (2014). Effects of constructivists' learning strategies on senior secondary school students achievement and retention in biology. Mediterranean Journal of Social Sciences. 5 (27), 627-633.

[5]. Grouws, D. A., \& Cebulla, K. J. (2000). Improving student achievement in mathematics. Geneva, Switzerland: International Academy of Education

[6]. Issa, N; Mayer, R.E; Schuller, M; Wang, E; Shapiro, M.B \& DaRosa, D.A (2013). Teaching for understanding in medical classrooms using multimedia design principles. Medical Education, 47(4), 388-396. doi: 10.1111/medu.12127

[7]. Lulee, S. (2010). Teaching for understanding framework in practice. EDDE 803: Teaching and learning in distance education. Athabasca University

[8]. Morocco, C.C. \& Bremer, C.D. (2003). Teaching for understanding. Research to Practice Brief 2(4). 1-7. Retrieved June 17, 2015 from www.ncset.org

[9]. Ogunkunle R.A. (2009). Teachers' effectiveness as emergent issue confronting quality mathematics education in primary schools in Rivers State. African Journal of Historical Sciences in Education, 5 (1\&2), 73-80.

[10]. Okoronka, U. A. \& Bitrus, Z. W. (2014). Effects of analogy instructional strategy, cognitive style and gender on senior secondary school students achievement in some physics concepts in Mubi Metropolis, Nigeria." American Journal of Educational Research 2(9). 788-792.

[11]. Perkins, D. (1994). Do students understand understanding? The Education Digest, 59 (5), 21-25.

[12]. Perkins, D. (2006). From idea to action. Course handout of teaching for understanding 2 at WIDE World program developed by Harvard Graduate School of Education. Retrieved from http://learnweb.harvard.edu/wide/ on October $27^{\text {th }} 2015$.

[13]. Perkins, D., \& Blythe, T. (1994). Putting understanding up front. (Cover story). Educational Leadership, 51 (5). 4-7.

[14]. Peter, O.I., Abiodun, A. P \& Jonathan, O.O. (2010). Effect of constructivism instructional approach on teaching practical skills to mechanical related trade students in western Nigeria technical colleges. International NGO Journal, 5(3), 59-64.

[15]. Ritchhart, R., \& Perkins, D. (2008). Making Thinking Visible. Educational Leadership, 65(5), 57-61.

[16]. Rivers State Senior Secondary Schools Board (2015). Students Enrolment for Third Term 2014/2015 academic session

[17]. Serio, M (2014). Engaging students in mathematical communication: Teaching for understanding. Retrieved from http://.www.hdl.handle.net/1807/67054 on $26^{\text {th }}$ October 2015.

[18]. Umoke, J.C. \& Nwafor, C.C (2014). Effects of instructional simulation on secondary school students' achievement in biology. Journal of Education Practice, 5(19) 101-110. www.iiste.org 